tumour and host indiscriminately) but might be followed by some other type of directed attack.

The list of suggestions relating to tumours with specific, or as we should now say, associated antigens, can now be filled out a little. Following the work of Professor Alexander and his colleagues one should, for example, add injection of RNA extracted from immune lymphoid cells-but in general, with a little juggling, the procedures which have been enumerated by Professor Mathé can be fitted quite well into this framework.

Here again, however, while the list of theoretical possibilities remains much the same, considerable advances have been made, and we are in a much better position today than we were even a few years ago to choose the right strategy in planning experiments and even to some extent in treating patients.

\section{Stimulating Immunological Defences}

Serendipity operates in this as in other branches of medicine and, as I have argued elsewhere, ${ }^{3}$ possibly immunotherapeutic procedures have sometimes been employed inadvertently. The administration of Coley's fluid to patients with malignant lymphomas and bone sarcomas is a possible example. More recently the use of simple mastectomy followed later by radiotherapy in the treatment of breast cancer, which as all the world knows we owe to Professor McWhirter, may conceivably stimulate immunological defences against residual tumour cells. The same applies also to the use of preliminary high-dose radiotherapy in the treatment of osteosarcoma. This was introduced by Sir Stanford Code with the object of sparing the patient a mutilating operation that would have no chance of curing him if the tumour had already become disseminated, but the results suggest-though they certainly do not prove-that this method of treatment actually carries a slightly better prospect of curing this dreadful disease. It is only fair to add that the suggestion is mine; $;^{3}$ Sir Stanford and his colleague Mr. E. S. Lee, with exemplary caution, have refrained from making any such claim.

It is widely believed that immunotherapy, if it is to be of any value in cancer, should be used when the bulk of the tumour has been removed surgically, or destroyed by other means such as irradiation or chemotherapy, and the patient (unless he has in fact been cured) has what I have called minimal residual cancer. ${ }^{4}$ Dr. Hamilton Fairley expressed this view yesterday and it is certainly supported by the work of Professor Mathé. As Professor Buttle pointed out in yesterday's discussion, however, if the augmented host resistance which appears to be concerned in the disappearance of Burkitt's tumours of maxi proportions following what one can only describe as mini-chemotherapy is immunological in nature, then in this respect (as, one might add in so many others) this tumour is exeptional.

If immunotherapy is to be used in patients with minimal residual cancer it is of paramount importance that the procedure should, at least, do no harm. Dr. Hamilton Fairley, in discussing his work on melanoma, told us he had found no evidence to suggest that the treatment used might stimulate the production of blocking antibody-and in consequence enhance the growth of the tumour-but this is still in my view a possibility to be seriously considered in every proposed clinical trial. When, several years ago, Boak and $\mathbf{I}^{5}$ found that the growth of intrastrain transplants of a mouse mammary carcinoma could be inhibited by treating the recipient by injection of killed cultures of Corynebacterium parvum we considered using this agent as an addition to standard procedures in the treatment of early human breast cancer. But the fear of producing enhancement held us back, and it is now proposed that the first clinical trials with $C$. parvum should be in patients with tumours carrying a much worse prognosis. Moreover, in my view, trials of this and other forms of immunotherapy should no longer be planned on a purely empirical basis. As I have already reminded you, the way is now becoming open to us to define the immunological defect operating in individual patients, and we should plan our attack accordingly. Of course, the immunological situation may change during the course of treatment, but this does not obviate the need for planning; rather, it imposes on us the task of continued reassessment and a readiness to change our protocol as the need arises.

REFERENCES

1 Woodruff, M. F. A., Lancet, 1964, 2, 265.

World Health Organization Technical Report Series, 1966, No. 344

Woodruff, M. F. A., Annals of the Royal College of Surgeons of England, $1969,44,299$.

4 Woodruff, M. F. A., Immex, Special Annual, 1969, p. 621.

5 Woodruff, M. F. A., and Boak, J. L., British fournal of Cancer, 1966, 20, 345.

\title{
Immunological Treatment of Leukaemias
}

\author{
GEORGES MATHÉ,* M.D.
}

Immunotherapy is the most recently introduced method for treating leukaemia, and probably it can be greatly developed during the next few years. Depending on whether antibodies or immunocompetent cells (lymphocytes) are administered or whether the body's own immune defences are stimulated, immunotherapy is called, respectively, passive, adoptive, or active.

\section{Passive Immunotherapy}

So far, valid trials of passive immunotherapy have not been made in man. For such trials to be acceptable cytotoxic

\footnotetext{
* Professor, Institut de Cancérologie et d'Immunogénétique, Hôpital Paul-Brousse, 94 Villejuif, France.
}

antibodies would have to be separated from the antibodies which "enhance" tumour growth, and then given alone. In patients with choriocarcinoma we have shown that enhancement antibodies do exist in man, ${ }^{12}$ and these could enhance the proliferation of neoplastic cells. From the results of studies at present being carried out in our laboratory, ${ }^{3}$ we hope that passive immunotherapy may eventually be used as a method of destroying tumour cells.

\section{Adoptive Immunotherapy}

Adoptive immunotherapy is based on the antitumour effect of the graft-versus-host reaction. We have shown this antitumour effect in studies on mice carrying the L 1210 grafted 
leukemia, ${ }^{4-6}$ the Charlotte Friend viral leukemia, ${ }^{78}$ and the spontaneous AkR leukaemia. ${ }^{910}$ This method has the disadvantage of being complicated by the general effects of this graft-versus-host reaction-namely, the development of secondary disease.

Good results with only slight risks can be obtained in animals when the lymphocyte donors can be specifically immunized against the tumour antigens. ${ }^{11}$ Nevertheless, at present this system cannot be applied to man, and attempts can consist only of non-specific adoptive immunotherapy.

Remissions, generally of short duration, have been obtained in man by the transfusion of allogeneic lymphocytes. ${ }^{12}{ }^{13}$ Very long remissions were obtained after grafts of allogeneic bone marrow (owing to the lymphocytes produced by the graft proliferating in the host). ${ }^{14-10}$

\section{Active Immunotherapy}

Active immunotherapy consists of stimulating the immune defences of the body against the tumour cells; it can be either non-specific (by giving immunological adjuvants) or specific, by injecting tumour cells whose antigens have been inactivated by irradiation in vitro.

Studies in mice have shown that immunotherapy can be effective even when it is given after the graft of L 1210 leukaemia. ${ }^{19} 20$

Generally tumour cells are immunotherapeutically more active than B.C.G., which is the best adjuvant so far available; but B.C.G. and tumour cells given together are more active than when each is given alone. Furthermore, B.C.G. is more active if given in several doses rather than as a single dose; on the other hand, leukaemic cells are just as active when given as a single dose as when they are repeated. Effective immunotherapy is so efficient that it can cause a complete regression of leukaemic cell proliferation and cure the animals. Nevertheless, its effect is noticeable only when $10^{5}$ leukaemic cells or fewer have been grafted into the animal, and it is totally ineffective in larger grafts. We have confirmed this immunotherapeutic effect on two other tumoursthe Rauscher transplantable leukaemia and the E K1 transplantable leukaemia. ${ }^{21}$

The use of active immunotherapy in man would be justified only if the human leukaemic cells carried different antigens from those detected in all animal cancers studied so far. From studies using cytotoxicity, immunofluorescence, complement fixation, immune adherence, and lymphocyte transformation tests, antibodies active against their own leukaemic cells and against cells of other patients have been found in the serum of more than one-third of leukaemic patients. ${ }^{.2-}$

As a result of studies of spontaneous leukaemia in AkR mice, some authors have suggested that patients with acute leukaemia should be immunologically tolerant of their own tumour cells. Certain experimental findings, however, make us doubt whether this tolerance exists in spontaneous leukaemia of AkR mice. ${ }^{23}$ No such tolerance has been found in human leukaemia, and Orbach ${ }^{24}$ has shown that treatment with 6-mercaptopurine, methotrexate, or cyclophosphamide is capable of breaking immune tolerance.

\section{Therapeutic Trials}

These results in animals form the basis of therapeutic trials of this form of treatment in patients with acute lymphoblastic leukaemia. So that the least possible number of leukaemic cells are present initially the patient is first treated with chemotherapy, then with "complementary cell reducing chemotherapy" (comprising different drugs given sequentially and intrathecal chemotherapy combined with irradiation of the central nervous system).

Thirty leukaemic patients ${ }^{25}$ were divided at random after these two chemotherapeutic phases into four groups: (1) 10 patients were given no further treatment after stopping chemotherapy; (2) eight patients were treated with B.C.G.; (3) five patients were injected with leukaemic cells; and (4) seven patients were treated with B.C.G. and leukaemic cells. The 10 patients in the first group all relapsed; the average duration of their remission after stopping treatment was 66 days, the median between the 70th and 77th day, and the limits were 20-130 days. At 130 days after treatment had been stopped only nine of the 20 patients given immunotherapy had relapsed; this difference is highly significant $\left(x^{2}=6 \cdot 18\right.$, $P<0.02)$. By 1 September 1970 four other patients had relapsed. In this study most of the relapses were early, nine before the 100th day and five before the 30th day-findings which are similar to our studies in animals.

This suggests that more leukaemic cells remained after treatment than could be adequately controlled by active immunotherapy. Four relapses were late, one occurring on the 210th day, another on the 324th day, and another on the 950th day, which is comparable to some very late relapses seen in the experiments on mice. The fourth relapse, which occurred on the 315th day, was in a child in whom B.C.G. therapy had been discontinued 44 days previously because of severe and persistent phlyctenular keratoconjunctivitis. This late relapse answers the question whether this form of therapy must be prolonged indefinitely. Seven patients are still in remission more than two years after stopping chemotherapy, five for more than three years, and two for more than four years.

There was no significant difference between the group given B.C.G. (five relapses out of eight cases, one after stopping treatment) compared with those given leukaemic cells alone (three relapses out of five cases), or the combination of B.C.G. and leukaemic cells (five relapses out of seven).

This trial proves that active immunotherapy can effectively control acute lymphoblastic leukaemia. We now propose to use it on patients given initial chemotherapy aimed at reducing the number of leukaemic cells even further than we achieved using the sequential chemotherapy employed since 1964.

\section{REFERENCES}

Mathé, G., et al., Fournal of the National Cancer Institute, 1964, 33, 193.

Amiel, J. L., Mery, A. M., and Mathé, G., in Cell-bound Immunity, vol. 43, p. 197. Liege, University of Liege, 1967.

Motta, R., European fournal of Clinical and Biological Research, 1970 15,161

- Mathé, G., and Bernard, J., Revue Francaise d'Etudes Cliniques et Biologiques, 1959, 4, 442.

Mathé, G., Amiel, J. L., and Niemetz, J., Comptes Rendus Hebdomadaires des Séances de l'A cademie des Sciences, 1962, 254, 3603.

" Mathé, G., and Schwarzenberg, L., Europian fournal of Cancer, 1968

4, 211. . Amiel, J. Lend Friend, Ch, Bulletin du Cancer, 1962, 49, 416 .

Mathé, G., and Amiel, J. L., Comptes Rendus Hebdomadaires des Seances de l'Academie des Sciences, 1964, 259, 4408.

de l'Academie des Sciences, 1964, 259, 4408.
Mathé, G., and Bernard, J., Bulletin du Cancer, 1958, 45, 289.

10 Mathé, G., Amiel, J. L., J., and Bernard, J., Bulletin du Cancer, 1960, 47, Mathé, G., Amiel, J. L., and Bernard, J., Bulletin du Cancer, 1960, 47,

1 Mathé, G., Schwarzenberg, L., Amiel, J. L., Pouillart, P., Schneider, M., and Cattan, A., in Advances in the Treatment of Acute (blastic) Leu kemias, ed. G. Mathé, vol. 1, p. 76. Heidelberg, Springer, 1970.

12 Schwarzenherg, L., et al., Isracl fournal of Medical Science, 1965, 1, 925.

13 Schwarzenberg, L., et al., American Fournal of Medicine, 1967, 43, 206.

14 Mathé, G., et al., Revué Francaise d'Etudes Cliniqués et Biologiques, 1959, 4, 675 .

15 Mathé, G., et al., Revue d'Hematologic, 1960, 15, 115.

16 Mathé, G., Amiel, J. L., Schwarzenberg, L., Cattan, A., and Schneider, M., British Medical Fournal, 1963, 2, 1633.

17 Mathé, G., et al., Blood, 1965, 25, 179 .

18 Mathe, G., tt al., Blood, tion, tion, ed. J. Dausset, and

19 Mathé, G., Rèue Francaise d'Etudes Cliniques et Biologiques, 1968, 13, 881 .

20 Mathé, G., Pouillart, P., and Lapeyraque, F., British Fournal of Cancer 1969, 23, 814

21 Mathé, G., Pouillart, P., and Lapeyraque, F., Experientia, 1970, in press. 22 Doré, J. F., et al., Lancet, 1967, 2, 1396.

23 Doré, J. F., and Mathé, G., European fournal of Clinical and Biological Research, 1970, 15, 81

24 Orbach-Arbouys, S., Etudes Cliniques et Biologiques, 1968, 13, 1014.

25 Mathé, G., et al., Lancet, 1969, 1, 697 